\title{
A CONTRIBUIÇÃO DA ECONOMIA SOLIDÁRIA NO DESENVOLVIMENTO LOCAL: A REALIDADE DAS COMUNIDADES DA REGIÃO DA AMUREL
}

Ivone Junges ${ }^{1}$

Ramon De Souza Cardoso ${ }^{1}$

Rodney Wernke ${ }^{1}$

${ }^{1}$ Universidade do Sul de Santa Catarina (UNISUL) 


\section{A CONTRIBUIÇÃO DA ECONOMIA SOLIDÁRIA NO DESENVOLVIMENTO LOCAL: A REALIDADE DAS COMUNIDADES DA REGIÃO DA AMUREL}

Resumo: A economia solidária se destaca na região da Amurel (Associação dos Municípios da Região de Laguna), sul de Santa Catarina, onde existem comunidades pobres e com potencial para o desenvolvimento de empreendimentos sociais. A pesquisa visa estudar os impactos econômicos, sociais e ambientais da economia solidária na região da Amurel por meio de um estudo qualitativo utilizando entrevistas semiestruturadas com os participantes dos empreendimentos sociais, profissionais de instituições que apoiam a economia solidária na região. Os empreendimentos se apresentaram benéficos nas esferas social, econômica e ambiental; possuem potencial para promoção da prática da economia solidária e das externalidades positivas inerentes a essa atividade. A região é beneficiada com a economia solidária em conformidade com os princípios que regem a atividade; entretanto, a prática da economia solidária na região é recente e demanda tempo para os empreendimentos aprimorarem a comercialização e a integração com a comunidade para maximizarem ganhos socioeconômicos.

Palavras chave: Empreendedorismo social. Economia solidária.

\section{Introdução}

A pesquisa estuda as externalidades positivas e negativas da economia solidária na região da Amurel (Associação dos Municípios da Região de Laguna), Santa Catarina. Apresenta como proposição identificar quais são os impactos positivos e negativos em termos econômicos, sociais e ambientais das atividades da economia solidária na economia real e, por consequência, na vida das pessoas que são beneficiadas com o empreendedorismo social na região estudada. Para isso contou com a experiência de um grupo de pesquisa da Unisul e de profissionais ligados à economia solidária da universidade e da comunidade regional.

A economia solidária tem se destacado na região da Amurel nos últimos cinco anos, pois a região possui bairros onde vivem parte considerável da população com níveis sociais considerados pobres economicamente, mas que apresentam potencial empreendedor.

Nessas comunidades existem registros de várias iniciativas assistencialistas e de apoio às famílias. Entretanto, nem todas dessas atividades estão ligadas à economia solidária e ao empreendedorismo social. $\mathrm{O}$ estudo mapeou quais atividades estão relacionadas aos contextos da economia solidária e do empreendedorismo social. Quais tecnologias sociais são eficientes e quais não são eficientes para alavancar as comunidades e a economia real, bem como em termos de sustentabilidade socioambiental.

Assim, a pesquisa mensurou os impactos que as tecnologias sociais geram na economia local, tendo como premissa a economia solidária, cujo objetivo principal é empoderar as pessoas com competências que lhe permitam gerar o sustento e a melhoria da qualidade de vida. Contribuindo para o crescimento da comunidade e, por consequência, a geração do desenvolvimento local. (MELO NETO; FROES, 2002; SALLES, 2002).

O objetivo geral desta pesquisa foi estudar os impactos econômicos, sociais e ambientais da economia solidária nas comunidades da região da Amurel.

Para auxiliar e nortear a realização do objetivo geral, foram estabelecidos os seguintes objetivos específicos: 1. Estudar na literatura os principais autores relacionados ao tema 
empreendedorismo social e economia solidária, inovação social, desenvolvimento local, sustentabilidade socioambiental e externalidades econômicas (positivas e negativas) a partir das tecnologias sociais. 2. Mapear as atividades desenvolvidas no contexto da economia solidária nas diferentes comunidades da região da Amurel. 3. Propor uma metodologia para mensurar as externalidades econômicas da economia solidária nas comunidades estudadas. 4. Identificar os cenários social, econômico e ambiental resultantes das atividades desenvolvidas pela economia social. 5. Propor diretrizes que potencializem a economia solidária nas comunidades estudadas a partir dos resultados da pesquisa.

É importante mensurar até que ponto a economia solidária tem contribuído efetivamente para gerar desenvolvimento socioeconômico na comunidade. Para isso tem-se a seguinte questão de pesquisa: Quais os impactos econômicos, sociais e ambientais da economia solidária na comunidade da Amurel?

\section{Discussões Teóricas}

Este tópico aborda teoricamente os principais conceitos relacionados a economia solidária. Os empreendimentos de economia solidária utilizam conceitos aplicados a empresas privadas como empreendedorismo, inovação e desenvolvimento econômico em razão do benefício social de seus participantes e da comunidade em que estão situados.

\subsection{Empreendedorismo social e economia solidária}

A sociedade moderna sofre de exclusões e dificuldades decorrentes do modelo econômico capitalista. Novos conceitos surgiram na busca por soluções. Dentre estes, as ideias de empreendedorismo social e economia solidária que possuem características distintas dos modelos privados e permanecem produtivos no mercado.

De acordo com Singer e Souza (2000), a economia solidária condena a ditadura do capital na empresa e o poder proporcionado pelo direito de propriedade dos meios de produção. A economia solidária beneficia a todos os envolvidos na atividade sem deixar de fazer parte do sistema capitalista vigente. Ela acomoda a dimensão social com o comportamento econômico tradicional, levando em consideração os problemas sociais, os países, as comunidades e seus contextos (FAYOLLE; MATLAY, 2010). Em muitas economias liberais, as necessidades sociais não são atendidas pelo Estado ou pelo setor público. Nessas economias a economia solidária utiliza dos mecanismos do mercado para atender as demandas sociais (MAIR, 2010).

O empreendedorismo trata do início de uma organização com diferentes finalidades realizadas por um empreendedor. Dornelas (2008, p. 22) define como: “[...] o envolvimento de pessoas e processos que, em conjunto levam à transformação de ideias em oportunidades".

A natureza do empreendedorismo é descrita como um fenômeno, onde o empreendedor se localiza dentro de um sistema em que a prática empreendedora deve desenvolver novas formas distintas ao modelo industrial presente nas nações desenvolvidas. Essas novas formas de empreendedorismo devem corresponder as demandas sociais e econômicas e serem adequadas também aos países em desenvolvimento (FAYOLLE; MATLAY, 2010).

O empreendedorismo social é uma vertente do empreendedorismo em que os envolvidos inovam para gerar produtos e serviços cujo lucro resulte na melhoria do ambiente onde se está inserido (GALVÃO, 2010). O empreendedorismo social utiliza o modelo de autogestão, onde as decisões são tomadas coletivamente por meio de assembleias e, se necessário, ocorrem eleições para definir os dirigentes do negócio. A gestão ocorre por meio do protagonismo de 
todos na tomada de decisões e na definição dos rumos e estratégias do empreendimento solidário (BORGES, 2015).

No Brasil, as ideias de economia solidária surgiram com os imigrantes europeus que já haviam conhecido cooperativas, além da inspiração oriunda dos ideais da Revolução Francesa (ARROYO; SCHUCH, 2006). Nas décadas de 1980 e 1990, o país se desindustrializou e com isso milhões de postos de trabalho foram perdidos, resultando no desemprego em massa e acentuando a exclusão social. Nesse contexto, a Cáritas ${ }^{1}$ financiou milhares de Projetos Alternativos Comunitários, posteriormente uma parte destes projetos passaram a ser empreendimentos de economia solidária (SINGER, 2002).

De acordo com o Ministério do Trabalho e Emprego (BRASIL, 2006), os empreendimentos econômicos solidários são caracterizados como organizações:

\begin{abstract}
a) coletivas - serão consideradas as organizações suprafamiliares, singulares e complexas, tais como associações, cooperativas, empresas autogestionárias, clubes de trocas, redes, grupos produtivos, etc.; b) cujos participantes ou sócios(as) são trabalhadores(as) dos meios urbano e rural que exercem coletivamente a gestão das atividades, assim como a alocação dos resultados; c) permanentes, incluindo os empreendimentos que estão em funcionamento e aqueles que estão em processo de implantação, com o grupo de participantes constituído e as atividades econômicas definidas; d) que disponham ou não um registro legal, prevalecendo a existência real; e e) que realizam atividades econômicas que podem ser de produção de bens, prestação de serviços, de fundos de crédito (cooperativas de crédito e os fundos rotativos populares), de comercialização (compra, venda e troca de insumos, produtos e serviços) e de consumo solidário.
\end{abstract}

O empreendedor social não busca o sucesso de vendas como acontece no empreendedorismo privado. A medida de sucesso se dá pelo impacto social, o número de pessoas beneficiadas com a proposta no programa ou projeto de empreendedorismo social. (MELO NETO; FROES, 2002). Lisboa (2005) afirma que para avaliar uma empresa solidária é necessário construir indicadores em três níveis: 1) ambiental - indicadores de sustentabilidade; 2) social - indicadores de gênero e etnia assim como as condições de vida das pessoas envolvidas; 3) econômico - indicadores das condições de trabalho, diferenças nos rendimentos, prática do consumo responsável solidário, coletividade no processo de decisões e transparência.

O limite da economia solidária não é obrigatoriamente o quanto é capaz ou não de substituir o modelo econômico dominante, mas sim de seu potencial pedagógico de estabelecer diálogos e causar um amadurecimento político para se alcançar uma economia plural (COSTA; CARRION, 2009).

\title{
2.2 Inovação social e desenvolvimento local
}

O conhecimento em todas as suas formas passou a desempenhar papel importante nos processos econômicos. A inovação passou a ser um investimento mais rentável do que alguns investimentos físicos. Ela providencia uma difusão mais rápida do conhecimento e descobre novas maneiras de produzir bens ou fornecer serviços (ORGANIZAÇÃO PARA COOPERAÇÃO E DESENVOLVIMENTO ECONÔMICO, 1996).

A Organização para Cooperação e Desenvolvimento Econômico (2005) em seu Manual de Oslo define que dentre os objetivos econômicos das inovações estão: a melhoria da qualidade do produto, reduzir os custos e danos ao meio ambiente, manter a participação no mercado e

\footnotetext{
${ }^{1}$ Organismo da Conferência Nacional dos Bispos do Brasil (CNBB).
} 
melhorar as condições de trabalho. O modelo de inovação para o bem social busca solucionar problemas ou gerar oportunidades para uma comunidade. Essas mudanças se dão mais por comportamento do que por mudanças em tecnologia ou de mercado (JÉGOU; MANZINI, 2012).

A necessidade por novos métodos de auxiliar os indivíduos a obterem melhores condições de vida e melhorar o aproveitamento dos recursos naturais leva a busca por inovações nos processo e iniciativas de âmbito econômico e social.

O Serviço Social da Indústria (SESI) (2015) define que: "a Inovação Social se refere ao desenvolvimento de processos, produtos e serviços que permitam a inclusão social, geração de trabalho e renda e, sobretudo, promovam a qualidade de vida das pessoas".

De acordo com Farfus, et al (2007), as inovações sociais podem possuir um número infinito de formas, como por exemplo: o trabalho no terceiro setor, o trabalho em organizações criadas para atender situações de emergência, trabalhos cooperativos e ações temporárias desenvolvidas pela sociedade civil.

Lastres e Cassiolato (2003) reconhecem a inovação como fator de competitividade sustentável. Também é associado a transformações e ao desenvolvimento econômico da região.

Desenvolvimento econômico é um termo distinto de crescimento econômico, sendo o primeiro o aumento da capacidade produtiva, calculado no Produto Interno Bruto e no Produto Nacional Bruto. O desenvolvimento econômico trata do crescimento econômico acompanhado da melhoria do padrão de vida da população e mudanças na estrutura econômica e social possibilitando uma melhor distribuição de riquezas (SANDRONI, 1999).

Perroux (1967 apud SANTOS, 2002) defende que o desenvolvimento econômico ocorre pela concentração em determinadas regiões, manifestando-se com intensidades variáveis. $\mathrm{O}$ autor também acredita que a concentração é parte fundamental do desenvolvimento e crescimento econômico, sendo assim, para se conseguir expandir o desenvolvimento, esse deve ser por meio da organização consciente dos meios de propagação do polo de desenvolvimento.

Diante dessa realidade, a questão do desenvolvimento deve ser abordada também em regiões em menor escala como comunidades. O desenvolvimento local é definido por Amaro (2009, p. 108) como "o processo de satisfação de necessidades e de melhoria das condições de vida de uma comunidade local, a partir essencialmente das suas capacidades, assumindo a comunidade o protagonismo principal nesse processo e segundo uma perspectiva integrada dos problemas e das respostas".

Os indicadores econômicos podem ter seu significado pouco representativo para a realidade local, pois é comum que eles não avaliem condições sociais. O desenvolvimento deve considerar a individualidade da região, assim como as capacidades e fraquezas sociais e econômicas para possibilitar a aplicação de um plano que atenda às necessidades específicas.

\subsection{Sustentabilidade socioambiental}

O crescimento econômico traz resultados indesejados ao meio natural, como sua demanda por recursos e espaço, além da geração e distribuição de poluentes no ambiente. A sociedade sofre esses impactos através da redução da qualidade de vida e a escassez de recursos naturais.

A sustentabilidade é definida por Alva (1997 apud Melo Neto e Froes, 2002, p. 108) como:

[...] um conceito ecológico - isto é, como a capacidade que tem um ecossistema de atender às necessidades das populações que nele vivem - ou, como um conceito político que limita o crescimento em função da dotação de recursos naturais, da 
tecnologia aplicada no uso desses recursos e do nível efetivo do bem-estar da comunidade.

Os problemas ambientais possuem uma ligação com a desordenada ocupação urbana e os métodos degradantes em que estão submetidos os trabalhadores do campo e da cidade. Assim, é necessário buscar alternativas que garantam maior equilíbrio nas relações inter-regionais e na distribuição populacional (SILVA, 2008).

A ideia de sustentabilidade também é aplicada ao meio social:

[...] refere-se ao desenvolvimento e tem por objetivo a melhoria da qualidade de vida da população. Para o caso de países com problemas de desigualdade e de inclusão social, implica a adoção de políticas distributivas e a universalização de atendimento a questões como saúde, educação, habitação e seguridade social. (SACHS, 1992 apud BARBOSA, 2008, p. 8).

De acordo com Ignacy Sachs (2007), para alcançar a sustentabilidade social é necessário basear-se nos valores primordiais de equidade e democracia, ou seja, a apropriação efetiva de todos os direitos humanos.

\subsection{Incubadoras sociais}

O processo de globalização econômica resultou em uma grande quantidade de desempregados no Brasil. Foram necessárias medidas alternativas para auxiliar os trabalhadores que sofreram com o fechamento de postos de trabalho.

De acordo com Singer e Souza (2000), a universidade é escolhida na maioria dos casos para tratar destes assuntos por não possuir o risco de mudanças com o tempo como no caso dos governos ou estar sob interesses de outros empreendimentos. A universidade como meio imparcial, com continuidade garantida e sem a espera de retorno financeiro.

As incubadoras sociais adotam metodologias diferentes das incubadoras de empreendimentos tradicionais (AUGUSTO, 2012, p. 24) explica que:

Não é possível utilizar as ferramentas de gestão e planejamento adotadas pelas empresas tradicionais. Cada uma atua de acordo com as especificações dos empreendimentos que apoiam e das regiões onde estão localizadas. Não há uma metodologia única, apesar de a maioria das incubadoras fazerem parte de redes. Mas algumas características são comuns, não há métodos rígidos e é realizada uma formação de empreendimentos não apenas quanto a aspectos econômicos e administrativos, mas também para a autogestão, inclusão social e economia solidária.

França Filho e Cunha (2009, p. 224) acrescentam à essa diferenciação entre a incubação empresarial e a incubação no âmbito da economia solidária o fato de que:

\footnotetext{
Em primeiro lugar, ela se volta geralmente a um público de baixa renda, que se organiza, na maior parte dos casos, em pequenas cooperativas. Em segundo lugar, nesse processo, normalmente não incidem taxas sobre os empreendimentos incubados, deixando elas de ser um componente importante dos subsídios. Em terceiro lugar, as instalações das incubadoras não abrigam iniciativas incubadas, à exceção de alguns casos de incubadoras públicas.
}

No Brasil, o Ministério do Trabalho e Emprego, por meio do Decreto n ${ }^{\circ} 7.357$, de 17 de novembro de 2010 criou o Programa Nacional de Incubadoras de Cooperativas Populares (PRONINC) para favorecer a criação e o acompanhamento de novos empreendimentos e fortalecer os já criados. 
As atividades das incubadoras sociais são essenciais para a criação e manutenção de empreendimentos de economia solidária, onde os envolvidos não possuem conhecimentos técnicos de gestão e desenvolvimento, assim como outras barreiras que dificultam as iniciativas populares. É crescente a prática desta atividade nas universidades brasileiras como atividade de extensão, compartilhando do conhecimento científico de forma prática para o benefício social.

Estudos similares foram realizados por França Filho e Santana Junior (2007), que avaliaram o impacto de três empreendimentos solidários na Bahia. Outro estudo similar foi realizado por Amorim (2005) ao abordar a experiência de um empreendimento solidário no Ceará.

\section{Procedimentos metodológicos}

A pesquisa é caracterizada como qualitativa e de cunho exploratório, que segundo Richardson (1999) estudos dessa natureza auxiliam a compreensão de fenômenos novos em realidades diferentes. Algumas informações foram analisadas quantitativamente, como os impactos na economia local, mas a pesquisa é essencialmente qualitativa.

Trata-se de uma pesquisa inédita na região, onde a economia solidária começa a se consolidar por meio de atividades que utilizam tecnologias sociais para potencializar e protagonizar melhoria da qualidade de vida nas comunidades.

Os sujeitos de pesquisa são: profissionais, instituições e grupos que trabalham com empreendedorismo social, incluindo economia solidária e economia criativa na região da Amurel, governo local, universidade, empresas e ONGs.

A amostra do estudo foi intencional para os dois níveis ou tipos de sujeitos de pesquisa refletindo as principais características do total do universo pesquisado

A coleta de dados foi realizada por meio de entrevistas e visitas nas comunidades ondem existem atividades da economia solidária. Para as entrevistas foram utilizados instrumentos de coleta de dados na forma de um formulário semiestruturado como roteiro para uma entrevista.

A análise dos dados foi qualitativa, incluindo análise de conteúdo por meio do referencial teórico utilizado no estudo para reforçar a análise dos dados coletados: depoimentos dos entrevistados (análise da percepção).

A amostra utilizada para descrever o empreendedorismo solidário na região da Amurel foi composta por oito empreendimentos de economia solidária e duas instituições que realizam atividades de apoio à economia solidária. Os empreendimentos sociais tiveram seus dados coletados por meio de seus gestores, as instituições de apoio foram por meio de seus coordenadores. Todas as entrevistas foram realizadas pessoalmente com os gestores e participantes dos empreendimentos e os profissionais das instituições de apoio. Para isso foram realizadas visitas nos empreendimentos e participação em feiras de economia solidária na região.

Os empreendimentos de economia solidária da região foram identificados através do fornecimento dos dados da ITCP (Incubadora Tecnológica de Cooperativas Populares) da Unisul (Universidade do Sul de Santa Catarina), que também informou sobre o papel da Cáritas na promoção de práticas de economia solidária. A coleta de dados ocorreu nos meses de abril a agosto de 2015. Neste período ocorreram três feiras de economia solidária na região que possibilitaram o contato com diferentes envolvidos nas atividades de economia solidária.

\section{Análise e Discussão dos Dados}

Neste tópico serão estudados os dados obtidos dos empreendimentos de economia solidária da região da Amurel. 


\subsection{Empreendimentos solidários estudados}

Devido a informalidade de muitos empreendimentos de economia solidária, não é possível estabelecer a quantidade exata de empreendimentos de economia solidária presentes na região da Amurel. Porém, parte destes é acessível por conta das instituições de apoio como a ITCP e por meio de encontros regionais e estaduais relacionados a economia solidária. $\mathrm{Na}$ região, tem-se aproximadamente onze empreendimentos solidários, sendo que para este estudo foram realizadas entrevistas com gestores e participantes de nove empreendimentos.

Os empreendimentos de economia solidária entrevistados na região da Amurel são:

a) Empreendimento A: empreendimento surgido de um grupo de mulheres de uma comunidade que já se reuniam para a produção de artesanatos na cidade de Tubarão. Posteriormente recebeu apoio da ITCP da Unisul e da Cáritas Diocesana de Tubarão. Seus produtos são artesanatos diversificados que se destacam pela utilização, em grande parte, de materiais reciclados.

b) Empreendimento B: empreendimento localizado na cidade de Tubarão. Fabricante de sabonetes, sabão sólido e líquido. Possui comprometimento com o meio ambiente e com a comunidade por meio da utilização de óleo de cozinha reciclado como insumo, a comunidade participa fornecendo o óleo aos participantes das atividades. Tanto a coleta como a comercialização são realizadas por meio de visitas de casa em casa nos bairros.

c) Empreendimento C: empreendimento de artesanatos em geral que está em atividade desde 2012. São ao todo 12 artesãs que produzem em seus domicílios. O empreendimento é localizado na cidade de Imbituba e possui um local para comercialização na cidade fornecido pela prefeitura.

d) Empreendimento D: empreendimento que atua há 8 anos produzindo crochês, tapetes e patchcolagem. As participantes produzem em seus domicílios e realizam reuniões semanais em um local cedido pela Igreja em Capivari de Baixo. Como insumos são utilizados tecidos, linhas e materiais reciclados.

e) Empreendimento E: grupo de 20 mulheres que produzem artesanatos em geral e doces. Atuam desde 2005 e possuem sede no município de Laguna. Maior parte da comercialização é realizada em feiras e por meio de contatos pessoais.

f) Empreendimentos F: dois empreendimentos que funcionam juntos na Casa das Artes, um local fornecido pela prefeitura de Laguna para a comercialização dos produtos. Trata-se do principal local no qual é trabalhado o artesanato no município de Laguna. Seus produtos são artesanatos em geral como peças de estante, toalhas de crochê e pesos de porta. Suas matériasprimas incluem conchas e outros insumos naturais. As participantes são todas mulheres que já trabalham juntas há 12 anos.

g) Empreendimento G: produtora informal de alimentos orgânicos e não-orgânicos que já atua desde 2000. Iniciaram suas atividades com a comercialização exclusiva de produtos orgânicos, o alto custo de produtos orgânicos levou o empreendimento a produzir também produtos nãoorgânicos visando o mercado local na comunidade do município de Laguna.

Todos os empreendimentos entrevistados realizam apenas a comercialização de produtos, estes, em grande parte, fabricados artesanalmente por grupos criados entre membros de uma comunidade. A comercialização desses produtos se dá em maior parte em feiras. Essas feiras ocorrem em diversos municípios pela região e são promovidos por instituições de apoio como a Cáritas e a ITCP da Unisul.

\subsection{Instituições e profissionais de apoio a economia solidária}


As Instituições de apoio a economia solidária auxiliam a criação e a manutenção de atividades de empreendimentos solidários. Foram realizadas três entrevistas com profissionais que trabalham com projetos ligados a economia solidária nas seguintes instituições:

a) Incubadora Tecnológica de Cooperativas Populares (ITCP) - para que o conhecimento gerado na universidade seja levado a comunidade, a incubadora foi criada em fevereiro de 2014 a partir de um projeto de extensão da Unisul. A ITCP acompanha os empreendimentos de economia solidária em formação, realiza assessoria técnica nas áreas de marketing, desenvolvimento de produto, nutricional, design, gerencial e financeiro (ESPINDOLA, 2014).

Em suas atividades são realizados diagnósticos de cada empreendimento de economia solidária para compreender a demanda deste. São realizados cursos de qualificações para gestão de processos administrativos, qualificação dos produtos e criação de cadeia e redes de consumo. A ITCP também promove feiras bimestrais gerenciadas utilizando o espaço da universidade.

b) Cáritas Diocesana de Tubarão - a Cáritas é um organismo da Conferência Nacional dos Bispos do Brasil (CNBB). Em relação a economia solidária, a Cáritas assume a execução do Centro de Formação e Apoio à Assessoria Técnica em Economia Solidária (CFES Nacional), um programa da Secretaria Nacional de Economia Solidária (CÁRITAS, 2013).

De acordo com a articuladora local, a Cáritas já atua há mais de 30 anos com a economia solidária. Trabalhando com miniprojetos de geração de trabalho e renda. Na região da Amurel já realizou a formação com onze empreendimentos no curso de gestão de negócio e o acompanhamento ao plano de negócio. Retomou a feira regional de economia solidária, realizada na cidade de Laguna e também criou o Fórum Regional de Economia Solidária, animado pela Cáritas, mas funciona como um órgão autônomo.

\subsection{Mapeamento das atividades da economia solidária na Amurel}

A Amurel é uma entidade que busca a integração político-administrativa, econômica e social de 18 municípios associados. O termo é comumente utilizado para descrever os municípios da microrregião de Tubarão, do Estado de Santa Catarina. Desta, não estão inclusos os munícios de Garopaba e Orleans (ASSOCIAÇÃO DOS MUNICÍPIOS DA REGIÃO DE LAGUNA, 2015). A distribuição dos empreendimentos de economia solidária na região da Amurel é mostrada na Figura 1.

Figuras 1 e 2 - Mapeamento das atividades de economia solidária na região da Amurel no ano de 2015 e Índice de Desenvolvimento Humano dos municípios no ano de 2010.
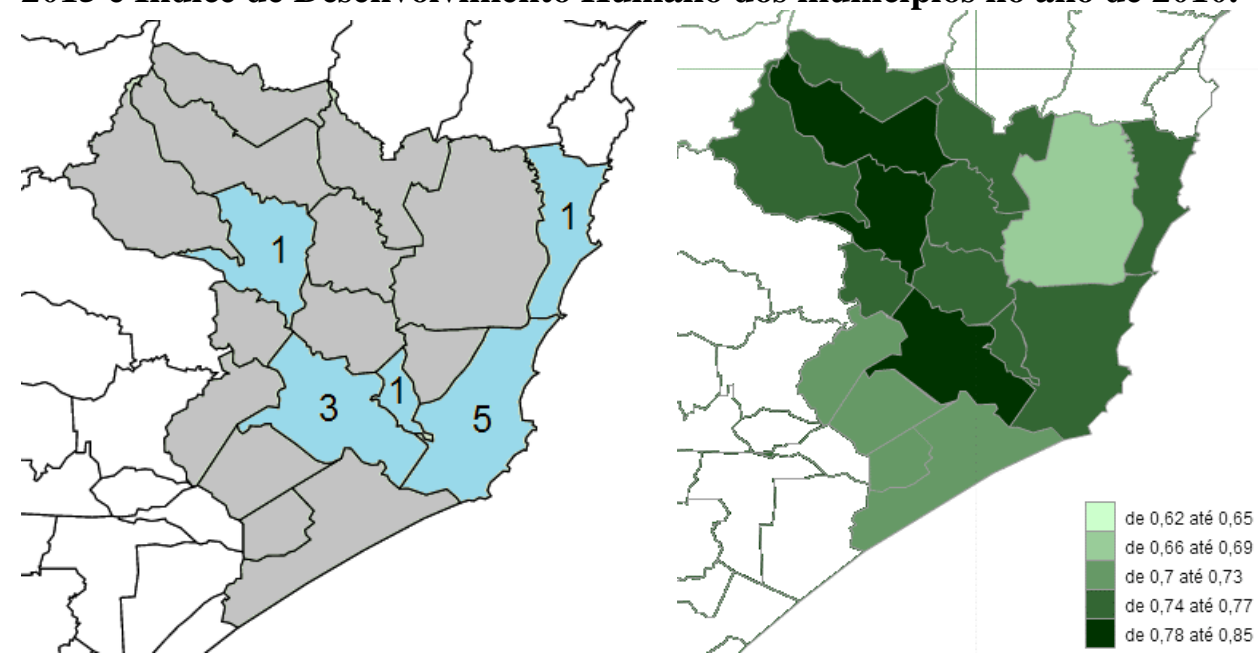

Fonte: elaboração dos autores com base nos dados coletados estatísticas do Instituto Brasileiro de Geografia e Estatística. 
Os municípios de Laguna e Tubarão possuem um maior número de empreendimentos de economia solidária atuantes tanto em atividades artesanais como produção de alimentos. Braço do Norte, Capivari e Imbituba dispõem de apenas um empreendimento social

A ausência de sedes locais das instituições de apoio afeta a distribuição dos empreendimentos pela região, pois tanto a Cáritas quanto a ITCP da Unisul estão situadas na cidade de Tubarão. Os fatores que justificam a localização dos empreendimentos não impedem que as práticas de economia solidária sejam expandidas aos municípios vizinhos, mostrando assim, uma potencialidade de expansão.

Os dados sobre contingencia populacional e número de empreendimentos de economia solidária são pouco significativos para identificar demandas e potenciais nas áreas de economia solidária. Pois, como estas estão atreladas a um compromisso social, é necessário compreender as condições sociais, econômicas e ambientais destes municípios.

O Índice de Desenvolvimento Humano (IDH) é, de acordo com o Programa das Nações Unidas para o Desenvolvimento (ORGANIZAÇÃO DAS NAÇÕES UNIDAS, 2015) como "[...] uma medida resumida do progresso a longo prazo em três dimensões básicas do desenvolvimento humano: renda, educação e saúde”.

O IDH mais baixo da região é situado no município de Imaruí, que apesar de apresentar uma considerável população não foi descoberta nenhuma iniciativa de empreendedorismo social. O que possibilita a investigação da criação de iniciativas de economia solidária moldadas a proporcionar melhorias em tais condições. Uma possibilidade seria a de inserção social e econômica da população indígena do município.

\subsection{Cenários social, econômico e ambiental}

A economia solidária apresenta progresso nas questões sociais pela inclusão de profissionais no sistema produtivo, tendo como destaque a igualdade de gênero. A igualdade entre sexos e a valorização da mulher é um dos objetivos do milênio estabelecido pela Organização das Nações Unidas. Uma das dimensões para alcançar essa meta é fornecer recursos e oportunidades econômicas como emprego e renda, pois, em relação a empregabilidade, as mulheres são mais propensas ao desemprego (ORGANIZAÇÃO DAS NAÇÕES UNIDAS, 2005). No cenário da economia solidária em Santa Catarina, as mulheres também são uma minoria que representam $33 \%$ das profissionais que realizam tais atividades (KUYVEN; KAPPES, 2013).

De acordo com a professora que participa da coordenação pedagógica da ITCP, o perfil dos envolvidos são profissionais que já possuem habilidades para desenvolver produtos e serviços e querem potencializar seu ganho. A maioria possui condições socioeconômicas de maior vulnerabilidade e há predominância do gênero feminino. O professor e coordenador geral acrescenta que os participantes possuem baixo nível de escolaridade e muitos são semianalfabetos. Há participantes que conciliam a atividade com outra ocupação.

O relacionamento com a comunidade é descrito pelos entrevistados da seguinte forma: Quadro 1 - Relacionamento da comunidade com o empreendimento de economia solidária de acordo com os participantes

\begin{tabular}{|l|l|}
\hline Empreendimento: & Fala: \\
\hline Empreendimento A & $\begin{array}{l}\text { "Tem um bom relacionamento. Não é muito valorizado, } \\
\text { poderia ser mais." }\end{array}$ \\
\hline Empreendimento B & $\begin{array}{l}\text { "Carregamos o óleo, eles [comunidade] deixam para nós no } \\
\text { mercado produtor." }\end{array}$ \\
\hline
\end{tabular}




\begin{tabular}{|l|l|}
\hline Artes da Natureza & $\begin{array}{l}\text { "Estamos incentivado a comunidade a vir para a economia } \\
\text { solidária." }\end{array}$ \\
\hline Artes do Mar & $\begin{array}{l}\text { "Não. Eles [comunidade] não nos ajudam e nós não ajudamos. } \\
\text { Somos uma associação." }\end{array}$ \\
\hline Empreendimento C & $\begin{array}{l}\text { "A gente participa de feiras no município. Qualquer evento } \\
\text { cultural ou feira a gente participa." }\end{array}$ \\
\hline Empreendimento D & "Eles [comunidade] reconhecem, mas tem pouco comércio." \\
\hline Empreendimento E & $\begin{array}{l}\text { "A gente tem uma parceria com a comunidade promovendo } \\
\text { cursos com o SENAR e a EPAGRI. A gente sede o espaço e } \\
\text { a gente sempre tá convidando mais participantes. " } \\
\text { "Vendemos de porta em porta e em feiras e conscientizamos } \\
\text { a comunidade dos benefícios dos produtos orgânicos." }\end{array}$ \\
\hline Empreendimento G
\end{tabular}

Fonte: elaboração dos autores com base nos dados coletados.

Porém, as atividades de economia solidária realizadas não deixam de ser um apoio financeiro e também inclusivo, pois, em processos como a incubação, as participantes recebem capacitação em áreas como gestão e finanças.

No âmbito econômico, os profissionais da ITCP consideram que as atividades de economia solidária da região auxiliam por fornecer um maior poder econômico aos participantes, proporcionando maior acessibilidade a necessidades básicas e incentivando o consumo e o desenvolvimento econômico local, além de fornecer saberes relacionados à economia como finanças e fluxo de caixa aos indivíduos com pouca escolaridade.

Em relação ao meio ambiente, os empreendimentos apresentam atuação satisfatória pela reutilização dos restos gerados no processo de produção do produto. No caso de muitos dos empreendimentos estudados, tratam-se de resíduos sólidos. A reciclagem de resíduos é importante porque muitos dos resíduos inorgânicos oriundos de atividades industriais são difíceis de serem reciclados naturalmente (VEIGA, 2004).

$\mathrm{Na}$ visão da entrevistada que participa da coordenação da ITCP é necessário entender que as ações ambientais dos empreendimentos de economia solidária se caracterizam em três níveis: "1. Necessita ser sensibilizado a práticas sustentáveis; 2. Sensibilizado, porém não possui conhecimentos específicos; 3 . Trabalho qualificado em relação as práticas sustentáveis." A incubadora auxilia na inserção de estratégias de sensibilização com bases sustentáveis de maneira que os empreendimentos possam chegar ao terceiro nível.

Em relação ao meio ambiente todos os empreendimentos estudados se apresentaram benéficos, principalmente em razão de seus diversos insumos naturais e/ou reciclados e pela minimização do desperdício de materiais. Como demonstrado no quadro 2:

Quadro 2 - Ações sustentáveis adotadas pelos empreendimentos de economia solidária de acordo com os participantes

\begin{tabular}{|l|l|}
\hline Empreendimento: & Ação: \\
\hline Empreendimento A & $\begin{array}{l}\text { "A gente procura reciclar, reaproveitar o máximo possível dos } \\
\text { produtos." }\end{array}$ \\
\hline Empreendimento B & $\begin{array}{l}\text { "Nós fizemos muita coisa. A gente recicla o óleo. Reciclamos } \\
\text { garrafa pet, jornal também." }\end{array}$ \\
\hline Artes da Natureza & $\begin{array}{l}\text { "É muito difícil sobrar porque sobra a gente reaproveita, os } \\
\text { mínimo pedacinho a gente reaproveita." }\end{array}$ \\
\hline Artes do Mar & $\begin{array}{l}\text { "A gente recicla todas as matéria prima. Basicamente o que a } \\
\text { natureza não quer a gente pega. A gente faz o luxo do lixo." }\end{array}$ \\
\hline Empreendimento C & "A gente produz outro produto com o que sobra." \\
\hline
\end{tabular}




\begin{tabular}{|l|l|}
\hline Empreendimento D & $\begin{array}{l}\text { "Aproveitamos tudo. Retalhos, tudo. Esses fuxico são tudo } \\
\text { feito de retalhinho." }\end{array}$ \\
\hline Empreendimento E & $\begin{array}{l}\text { "Tudo é reaproveitado. Por isto trabalhamos com uma } \\
\text { variedade de artesanatos, aproveitamento de fios e tecidos. } \\
\text { "Tudo é reaproveitável. A gente também reaproveita o lixo, } \\
\text { doamos para os outros. Usamos tudo o que dá." }\end{array}$ \\
\hline
\end{tabular}

Fonte: Elaboração dos autores com base nos dados coletados.

Além do valor monetário produzido pelos trabalhos, também deve ser considerado o rendimento moral, que legitima sua reinvindicação de respeito da comunidade e de seus familiares. O que o também é dignificante através da honra, ou seja, o direito ao orgulho de si mesmo (SARTI, 1996).

A quadro 3 descreve as falas dos envolvidos na economia solidária sobre a satisfação pessoal em desempenhar uma função à qual gostam e são capacitadas a desempenhar.

Quadro 3 - Benefício moral aos envolvidos nas atividades

\begin{tabular}{|l|l|}
\hline Empreendimento: & Ação \\
\hline Empreendimento A & $\begin{array}{l}\text { "É ótimo, a gente socializa, tem intercâmbios, tem uma soma } \\
\text { de conhecimentos." }\end{array}$ \\
\hline Empreendimento B & "É maravilhoso. É muito bom se sentir útil." \\
\hline Artes do Mar & $\begin{array}{l}\text { "Ótimo, a gente sente muito a satisfação de fazer. A gente se } \\
\text { encontra com as amigas é muito bom." }\end{array}$ \\
\hline Artes da Natureza & $\begin{array}{l}\text { "Tudo o que nós fizemos é com amor. Cada peça que olhamos } \\
\text { já pensamos no que queremos fazer." }\end{array}$ \\
\hline Empreendimento C & $\begin{array}{l}\text { "Ajuda no crescimento da própria pessoa. A gente coloca } \\
\text { amor em tudo aquilo que faz." }\end{array}$ \\
\hline Empreendimento D & $\begin{array}{l}\text { "Todas gostam do trabalho e é uma alegria total. Nosso } \\
\text { trabalho tem uma amizade, a gente se dá muito bem." }\end{array}$ \\
\hline Empreendimento E & $\begin{array}{l}\text { "Já temos senhoras aposentadas e isso ajuda elas como terapia } \\
\text { ocupacional." }\end{array}$ \\
\hline Empreendimento G & $\begin{array}{l}\text { "O lucro é dividido a todos iguais. Não tem patrão, somos } \\
\text { solidária." }\end{array}$ \\
\hline
\end{tabular}

Fonte: Elaboração dos autores com base nos dados coletados.

Para a economia local, todos os empreendimentos, por realizaram atividades produtivas, se tornam benéficos por aumentar a renda e consequentemente o consumo local. Os casos de benefício notável se dão nos empreendimentos Artes do Mar, Nossa Terra e Empreendimento $\mathrm{C}$, estes já possuem local para comercialização definido e são reconhecidos publicamente como parte da cultura local. Os empreendimentos do setor alimentício apresentam um benefício econômico notável em relação a outros empreendimentos por comercializar produtos com maior demanda.

Nas palavras dos participantes, o benefício econômico se deu da seguinte forma.

Quadro 4 - Resultados econômicos do empreendimento

\begin{tabular}{|l|l|}
\hline Empreendimento: & Resultado: \\
\hline Empreendimento A & "É uma complementação de renda." \\
\hline Empreendimento B & "É pouco, mas ajuda. A felicidade não tem preço. " \\
\hline Artes da Natureza & $\begin{array}{l}\text { "Tá mal das pernas. Não temos verbas, pagamos por nosso } \\
\text { transporte e nossa alimentação [para as feiras]. Não queremos } \\
\text { dinheiro, queremos um local para trabalhar." }\end{array}$ \\
\hline
\end{tabular}




\begin{tabular}{|l|l|}
\hline Artes do Mar & $\begin{array}{l}\text { "Pouco, mas ajuda. Tem vez que dá mais, tem vez que dá } \\
\text { menos. }\end{array}$ \\
\hline Empreendimento C & "Ajuda na renda familiar." \\
\hline Empreendimento D & "Ajuda, não é muito, mas complementa." \\
\hline Empreendimento E & "Sim, claro. Gera um retorno financeiro também." \\
\hline Empreendimento G & "Ajuda muito em casa, ajuda muito o marido." \\
\hline
\end{tabular}

Fonte: elaboração dos autores com base nos dados coletados.

Com os dados coletados nos empreendimentos, foi notado que a atividade em seu viés econômico funciona como um complemento na renda familiar, pois, a prática como principal função e meio de sustento no atual cenário se apresenta pouco atrativa ainda pois existem poucas iniciativas na região.

\subsection{Diretrizes para potencializar a economia solidária}

Apesar de se apresentaram benéficas em muitos setores da sociedade. A prática da economia solidária pode ser potencializada na Amurel através de medidas tomadas por diferentes entidades/grupos como:

a) Governo - estabelecer políticas públicas para promoção das atividades de economia solidária e facilitar a legalização de cooperativas. Tornar o apoio a prática da economia solidária em uma política de Estado e não apenas de governo. Cunha (2002) acrescenta que o governo pode: criar condições favoráveis através da facilitação do acesso ao crédito, reduzir obstáculos legais e burocráticos, e melhorar a infraestrutura dos espaços urbanos para proporcionar um cenário favorável a criação de novos empreendimentos.

b) Universidades - expansão das atividades de economia solidária aos outros municípios da região. Desenvolvimento de projetos de pesquisa e extensão no âmbito da economia solidária por parte das demais universidades da região. Apoio para capacitação nas áreas de gestão e produção.

c) Entidades de apoio - proporcionar novas oportunidades ao empreendedorismo regional no âmbito da economia solidária e assessoramento técnico de entidades que já realizam tais fins para atividades privadas como o Serviço Brasileiro de Apoio às Micro e Pequenas Empresas (SEBRAE). Outras entidades também podem auxiliar por meio de projetos de aporte de capital e realização de feiras de economia solidária.

d) Comunidades - maior integração comunitária com grupos locais. Aperfeiçoamento da gestão dos empreendimentos da economia solidária. Atualmente existe a autogestão, sem procedimentos adequados para medir os custos e os ganhos reais. Também não existe planejamento estratégico para alavancar tais empreendimentos. O marketing é incipiente, não permitindo a ampliação dos mercados.

A economia solidária é um conceito de aplicação recente na região da Amurel e demanda tempo para sua consolidação e reconhecimento, a colaboração da comunidade e entidades de apoio é fundamental para sua manutenção e sustentabilidade.

\section{Considerações finais}

A pesquisa alcançou seu objetivo geral por meio das informações dos envolvidos nas atividades. Os demais objetivos específicos também foram alcançados, com algumas limitações, tais como a falta de dados quantitativos e o acesso à alguns empreendimentos de economia solidária. 
A economia solidária na região da Amurel apresenta resultados satisfatórios no âmbito econômico, proporcionando por maior poder econômico e incentivando o consumo local, e como consequência também estimula o desenvolvimento econômico da comunidade.

Na perspectiva social ele beneficia através da inserção de gênero no mercado, diferença que se apresenta como um desafio na sociedade atual, também proporciona a capacidade dos moradores da comunidade de desempenharem uma atividade econômica produtiva. É notável o desempenho na questão ambiental pela aplicação de práticas sustentáveis durante o processo de produção, tal como a administração consciente de seus recursos, reutilização de materiais descartáveis e outras medidas com comprometimento ambiental.

Em geral, as atividades são benéficas e condizem com os princípios da economia solidária, porém, as atividades de economia solidária são recentes e necessitam de tempo para consolidarem na região. Como são caracterizadas como geradoras de emprego e renda, a economia solidária não apresenta resultados negativos na comunidade da Amurel.

A informalidade dos empreendimentos e a falta de dados quantitativos limita a avaliação do benefício destas atividades, o que pode vir a ser abordado em novos estudos sobre o tema além da possibilidade de avaliar novos métodos de promoção a pratica da economia solidária como estudos sobre a formação de aglomerados econômicos na região.

\section{Referências}

AMARO, Rogério Roque. Desenvolvimento Local. In: HESPANHA, Pedro (Coord.). Dicionário internacional da outra economia. Coimbra: Almedina, 2009. 343 p.

AMORIM, Rizoneide. A economia solidária, um passo além da informalidade: a experiência de Dendê-Fortaleza-Ceará. Natal: UFRN, 2005.

ARROYO, João Cláudio Tupinambá; SCHUCH, Flávio Camargo. Economia popular e solidária: a alavanca para um desenvolvimento sustentável e solidário. São Paulo: Fundação Perseu Abramo, 2006. 111 p.

\section{ASSOCIAÇÃO DOS MUNICÍPIOS DA REGIÃO DE LAGUNA. Plano básico de} desenvolvimento regional. Disponível em:

<http://www.amurel.org.br/uploads/1522/arquivos/371635_Volume01.pdf > Acesso em: 06 ago. 2015.

AUGUSTO, Camila. Foco no social. Revista Locus, Brasília, Ano XVIII, no 68/69, p. 22-27. Setembro 2012.

BARBOSA, Gisele S. O desafio do desenvolvimento sustentável. Visões (Rio de Janeiro), v. 4, 2008.

BORGES, Thelma Pontes. Os atores da economia solidária: estudos sobre personalidade ética. 2015. Tese (Doutorado em Psicologia Escolar e do Desenvolvimento Humano) Instituto de Psicologia, Universidade de São Paulo, São Paulo, 2015. Disponível em: $<$ http://www.teses.usp.br/teses/disponiveis/47/47131/tde-12052015-124929/>. Acesso em: 05 ago. 2015. 
BRASIL. Decreto no 7.357, de 17 de novembro de 2010. Dispõe sobre o Programa Nacional de Incubadoras de Cooperativas Populares - PRONINC, e dá outras providências.

BRASIL. Ministério do Trabalho e Emprego. Anexo I, Portaria $\mathbf{N}^{\circ}$ 30, de 20 De Março de 2006. Brasília: Ministério do Trabalho e Emprego, 2006. Disponível em: < http://portal.mte.gov.br/data/files/FF8080812B35FA90012B45AB934E3623/sies_ANEXO_I _Portaria_Instituicao_SIES.pdf>. Acesso em: 7 fev. 2014.

CÁRITAS. Economia popular solidária. 2013. Disponível em: $<$ http://caritas.org.br/projetos/programas-caritas/economia-popular-solidaria〉. Acesso em: 21 jul. 2015.

COSTA, Pedro de Almeida; CARRION, Rosinha da Silva Machado. Situando a Economia Solidária no campo dos estudos organizacionais. Outra Economía, v. III, n. 4, p. 66-81, 2009.

CUNHA, Gabriela Cavalcanti. Economia solidária e políticas públicas: reflexões a partir do caso programa Incubadora de Cooperativas, da Prefeitura Municipal de Santo André, SP. 2002. Dissertação (Mestrado em Ciência Política) - Faculdade de Filosofia, Letras e Ciências Humanas, Universidade de São Paulo, São Paulo, 2002. Disponível em:

$<$ http://www.teses.usp.br/teses/disponiveis/8/8131/tde-23052005-101736/>. Acesso em: 17 ago. 2015.

DORNELAS, José Carlos Assis. Empreendedorismo: transformando ideias em negócios. 5 ed. Rio de Janeiro: Elsevier, 2008. v. 1. 267 p.

ESPINDOLA, Sara. Incubadora assessora seis empresas do litoral sul. Unisul Hoje, 2014. Disponível em: <http://www.unisul.br/wps/portal/unisul-hoje/Noticia/?id=218328>. Acesso em: 20 jul. 2015.

FARFUS, Daniele; ROCHA, Maria Cristhina de Souza; CARON, Antoninho, et al. Inovações sociais. Daniele Farfus (org.), Maria Cristhina de Souza Rocha (org.) ; Antoninho Caron ... [et al.]. Curitiba: SESI/SENAI/IEL/UNINDUS, 2007. 246 p. : il. ; 30 cm. (Coleção Inova; v. 2). 2).

FAYOLLE, Alain; MATLAY, Harry (Coord.). Handbook of Research on Social Entrepeneurship. Cheltenham: Edward Elgar Publishing Limited, 2010.

FRANÇA FILHO, Genauto Carvalho de; CUNHA, Eduardo Vivian da. Incubação de redes de economia solidária. In: HESPANHA, Pedro (Coord.). Dicionário internacional da outra economia. Coimbra: Almedina, 2009. 343 p.

FRANÇA FILHO, Genauto Carvalho; SANTANA JUNIOR, Gildásio. Economia solidária e desenvolvimento local: uma contribuição para redefinição da noção de sustentabilidade a partir da análise de três casos na Bahia. Salvador: 2007. 
GALVÃO, Elisel Bezerra. Empreendimento social. Brasília: 2010. Disponível em: <http://www.administradores.com.br/artigos/carreira/empreendedorismo-social/49170/> Acesso em: 15 de out. 2014.

JÉGOU, Françõis; MARZINI, Ezio. Collaborative services: Social innovation and design for sustainability. Disponível em: <http://www.experimenta.es/en/noticias/depth/collaborativeservices-social-innovation-and-design-sustainability-3715>. Acesso em: 19 out. 2014.

KUYVEN, Patrícia Sorgatto; KAPPES, Sylvio Antornio. II mapeamento da economia solidária região sul. 2013 (Cartilha informativa). 37 p.

LISBOA, Armando de Melo. Economia solidária e autogestão: imprecisão e limites. RAE. Revista de Administração de Empresas, São Paulo, v. 45, n.3, p. 109-115, 2005.

MELO NETO, Francisco Paulo de; FROES, César. Empreendedorismo social: a transição para a sociedade sustentável. Rio de Janeiro: Qualitymark, 2002.

ORGANIZAÇÃO DAS NAÇÕES UNIDAS. Taking action: Achieving Gender Equality and Empowering Women. Londres: Earthscan. 2005. 257 p.

ORGANIZAÇÃO DAS NAÇÕES UNIDAS. Programa das Nações Unidas para o Desenvolvimento. Desenvolvimento Humano e IDH. Disponível em: < http://www.pnud.org.br/IDH/DH.aspx >. Acesso em: 14 ago. 2015.

ORGANIZAÇÃO PARA COOPERAÇÃO E DESENVOLVIMENTO ECONÔMICO.

Manual de Oslo: Diretrizes para coleta e interpretação de dados sobre inovação. Brasília: 2005.

The OECD Jobs Strategy - Technology, Productivity and Job Creation, v.1, Paris. 2006. Disponível em: 〈http://www.oecd.org/els/emp/1868601.pdf>. Acesso em: 09 fev. 2015.

RICHARDSON, Roberto Jarry. Pesquisa social: métodos e técnicas. 3 ed. São Paulo: Atlas, 1999.

SACHS, Ignacy. Rumo à ecossocioeconomia: teoria e prática do desenvolvimento. São Paulo: Cortez, 2007472 p.

SALLES, Ricardo Henrique. Plano de negócios para cooperativas e associações. Rio de Janeiro: DP\&A: FASE, 2002.

SANDRONI, Paulo Novíssimo Dicionário de Economia. 3. ed. São Paulo: Best-Seller (Nova Cultural), 1999.

SANTOS, Alvaro Barbosa. Desenvolvimento regional e capital social: uma abordagem para a microrregião de Presidente Prudente/SP. In: XIII Encontro Nacional de Geógrafos, 2002.

SARTI, Cynthia Andersen. A família como espelho: um estudo sobre a moral dos pobres. Campinas: Autores Associados, 1996. 128 p. 
SERVIÇO SOCIAL DA INDÚSTRIA. A inovação social como parte do negócio.

Disponível em: <http://www.sesipr.org.br/inovacaosocial/a-inovacao-social-como-parte-donegocio-1-19619-162000.shtml>. Acesso em: 08 fev. 2015.

SILVA, Christian Luiz da (Org.). Desenvolvimento sustentável: um modelo analítico integrado e adaptativo. 2. ed. Petrópolis: Vozes, 2008. 176 p.

SINGER, Paul. Economia solidária versus economia capitalista. Sociedade e Estado, Brasília, v. 16, n. 1-2, p. 100-112, dez. 2001. Disponível em:

$<$ http://www.scielo.br/scielo.php?script=sci_arttext\&pid=S0102-

69922001000100005\&lng=pt\&nrm=iso >. Acesso em: 17 ago. 2015.

Introdução à economia solidária. São Paulo: Perseu Abramo, 2002. 127 p.

SINGER, Paul. SOUZA, André Ricardo. A economia solidária no Brasil: a autogestão como resposta a ao desemprego. São Paulo: Contexto, 2000. 360 p.

VEIGA, Vanêssa Veras da. Análise de indicadores relacionados à reciclagem de resíduos sólidos urbanos no município de Florianópolis. 2004. 140 p. Dissertação (Mestrado em Engenharia de Produção) - Programa de Pós-Graduação em Engenharia de Produção, UFSC, Florianópolis. 